\title{
Panel Commentary: Screening Applications
}

\author{
Brian Rush
}

Published online: 28 December 2007

(C) Springer Science + Business Media, LLC 2007

\section{Morning of Day Two}

Paul Niesink

Clinical Supervisor

Niagara Alcohol and Drug Assessment Service

One St. Paul Street, Suite 203

St. Catharines, Ontario

L2R 7L2

Wayne Skinner

Deputy Clinical Director, Addictions Program

Centre for Addiction and Mental Health

Addiction Programs

33 Russell Street

Toronto, Ontario

M5S 2S1

\section{Christine Bois}

Priority Coordinator, Concurrent Disorders

Centre for Addiction and Mental Health

33 Russell Street

Toronto, Ontario

M5S 2S1

\section{Steve Lurie}

Executive Director

Canadian Mental Health Association (Toronto)

180 Dundas Street West, Suite 2301

Toronto ON M5G 1 Z8

The online version the original article can be found at http://dx.doi.org/10.1007/s11469-007-9097-1.

B. Rush $(\bowtie)$

Health Systems Research and Consulting Unit, Centre for Addiction and Mental Health, Toronto, Canada e-mail: Brian_Rush@camh.net 
Paul Nesink: I work at an addiction service in the Niagara area and I would like comment on what we heard yesterday as well as this morning. Our agency is very much like Linda's in that we do a whole host of different addiction programs. Gambling is probably our newest one. We do the impaired driving program; we do drug and alcohol counselling, and we have a huge family component. The invitation today was extended, I think, primarily from some of the work we are doing with Brian and Garth on a couple of projects. One is the examination of the provincial assessment tools that is being done for the Ministry. There is also a second research project about integrating mental health screening questionnaires into addiction services.

I'm not going to belabour you with things that we already know. There are problems in our addiction treatment system, all of them around training, resources and staffing. Even the language that we use is always an issue; in other words one thing in one local treatment system means another thing in another. In the addiction system there used to be a program out in St. Thomas for people who had concurrent disorders. This is not a provincial resource anymore so we can't access those kinds of specialized programs. In our local setting it is really becoming one of those chicken and egg things. We will send a client to a psychiatrist or mental health service and a lot of times the feedback that we get is "When you are clean, you come back and see us", and I know that is a common comment both ways. I don't think this is really helping either of our service systems and that is why in a lot of our presentations this morning that talked about the use of multidisciplinary teams which really makes a lot of sense in filling that gap. In Niagara, we have a couple of physicians on board that are calling themselves "addictionologists" and they are working really well with this population. They are looking both at the mental health issues as well as the addiction issues. They also look at some of the things around titrating off medications and they run methadone clinics. Therefore, there is a wide range of different medical, psychiatric and addiction services that they provide, all in one stop. So we are very fortunate to have those people in Niagara.

An example of the way the system is supposed to work, but sometimes doesn't, is an initiative that we were involved in called CURA, Community University Research Alliance. It had about 20 professors from our local university and about 20 different community agencies involved. We all sat on a committee, we developed surveys, we administered them, and the end result was supposed to improve the community service practices for youth in the Niagara area. The problem is that the funding ran out after three years. We got the survey results and after the surveys were done there was no way to practically apply the information. The scads and scads of data that we had on these individuals were never used. It is still sitting there in the computers. It is being used by students in the university but to me it is a real glaring example of how things are supposed to work to continually improve upon services and treatment systems, but don't always work.

Linda has been a colleague of mine for years and I think if we had more people like Linda on board this would be a much better system for all of us. She brings a lot of expertise and her ideas presented today make a lot of sense. She was one of the driving forces for the provincial assessment tool protocols that we use in the province. That being said, there are some problems with some of the things that were done with those tools none of which were Linda's fault. I just want to bring up two examples of things I have dealt with this week and they happen week in and week out with the tools. We have a local judge who decides where and when people will go and he mandates on their bail orders or probation orders: "thou shalt attend this program". So assessment and placement in treatment throws out the whole admission/discharge criteria; it throws out the whole 
process. He has already made the screening, the assessment, and the decision as to where this individual needs to go. This individual presents and says forget this, I don't want to do that but I will anyway; so no motivation. So we have this whole concept of the mandatory referral and how useful is that placement with the limited resources within our continuum. So those things are really a problem.

Another example of how these tools have failed us in some ways is the perception of some programs that they are the necessary evil. The example that I bring is that I had a client show up in our office on Monday and said I am going to such-and-such a program. I have already done the intake. I have my admission date. You just have to finish the assessment tools so that I can get there. So the whole process again has been sidestepped and the assessment/referral agencies basically are brokering the referrals to the more intensive programs without proper screening and assessment being done. So those were some things that have happened within our system that need to be corrected and I hope that the evaluation that Garth and Brian are doing on the tools is going to help us with that.

One of the other things with the tools is when they were originally introduced to the province, there was a concept that you could enter any door and get the service. I am not as sure about other parts of the province, but generally that hasn't happened locally. A lot of the addiction services no longer administer the tools or do assessments for anyone other than people they intake into their own service. So that whole concept is a great concept, and I believe in it firmly, but resources for a lot of the detoxification and residential centres and halfway houses just weren't there to continue with that practice. So again it falls back to the assessment/referral service, which is our job, and we do what we can with that. Within our agency we have basically two ways of promoting this. Intake is a scheduled appointment. We are similar to Linda in that we have about a 4-6 week waiting period for a scheduled appointment. We also have a walk in service, which is kind of interesting especially when we use the "deli counter" process. We have an opening for about six walk-ins per afternoon for an assessment and we put the number out at noon and you have to come back at 1:00 PM. And lots of time there is way more than six people standing there, waiting for one of those tickets. So it is an attempt, but when you stand there and you see $8,9,10$ people, and you can only give out 6 numbers, it is a little disheartening the way the process works with such limitations on accessing our services.

The other part I'd like to reinforce today is the youth services, and the coordination of these services especially with the cut-off age at 18 for youth in mental health services in Ontario. We need to work together not only with our adult services in the treatment field, but also in the research and the assessment field. Just a few last comments. I really enjoyed Dr. Parikh's approach concerning what is treatable in addiction settings. He mentioned depression and anxiety which, if you talk to a lot of people who work in the addictions system, those are things that we deal with everyday with almost every client. We can do, and I'm going to quote Tony's presentation the other day, "the functional analysis of mental health systems and concurrent substance use". I thought that was a really intelligent way of putting it in terms of how we work with these people, and so many of them present and so many of our counsellors work on these issues with them. This is almost ingrained within the way we do the services within our program, and I'm sure within many of the addiction programs. To that extent we also do a concurrent group with our local community mental health service for panic disorders. It is a ten-week group and people are screened by the mental health service and they provide support as well as education to these individuals. We have been running it about 7-8 years now. It has been researched through CAMH and it is one of the shining stars we have left from the multiple different collaborations in which we were involved with mental health services. However, with funding and resources getting lower 
and lower those are the services that we have to claw back on. We have the mandated services that we are required by the Ministry to provide and those are the ones that we continue with.

From Julian's presentation I thought: "Wow, what a way to work as a system". I know in Niagara we do have one or two physicians who work collaboratively with us and I think that is something that hopefully the LHIN process here in Ontario will address because that is something that makes so much sense to me. The last piece I wanted to say is the family involvement piece, which is something that we really stressed with our younger population and have moved out into our adult population as well. It takes a lot of skill to work with families and couples and it is something that a lot of the veterans of our agencies had to learn to do along the road. However, to me it is one of the most valuable services that we can provide, since when you look at the context of addiction problems within a family it is not just the individual using that is affected. So we must give the family the tools and education and ways to work together collaboratively. Thank you very much.

Wayne Skinner: This morning I feel that we have heard from three very wise and knowledgeable change champions and from very different perspectives. I am going to make some comments about that and maybe use it as a springboard to say a few other things. I may also come back to our concurrent disorder experience here at the centre but I will leave it for the end and see how my time goes.

I think in Linda's presentation we see the whole experience with clinical assessment tools in addiction as a very interesting object lesson. It does prove that change can happen and it can be well managed, and that it can produce a set of problems as well. Paul mentioned some of them. So I think there are people out there who would still be all too happy to ambush this change process as well. That kind of dialectic is very interesting but this initiative has changed the field in some important ways. In reality it has introduced a really important idea and that is that the client is the client of the system. That is a pretty radical concept because what it is meant to facilitate is that the client can go through any door to get addiction service in Ontario. So as much as operationally it produces a bunch of headaches for people - and I think it hasn't been well resourced, and it has been imposed on people in some ways even with best efforts to train - I think that it is an important thing to be pursuing.

With concurrent disorders of course, we need to ask ourselves, "What is the system?" Is it just addictions or a broader system that we want the client to be part of? I think we are actually developing a bigger notion of the system. Of course, you know there never has been a system, in a certain sense. There is really no system out there, and we have a bunch of people in desperate ways trying to do the best that they can.

The other thing about change is that it is more important to notice where the engine is going than the caboose. When you have things happen, it really is important to know where they are heading. So with any change, there is always going to be a caboose, and there will be people back there saying, "Where the heck are we going? and why are we doing it?", and not really knowing. They may also be trying to find the brake as well. When change is happening it really is important to know who is up at the front of the train and who can make it happen. The provincial assessment tools project could be approached as an object lesson in terms of what worked well and what could have worked better.

In terms of Sagar's presentation, it is a wonderfully strong call for us to be pragmatic. Certainly for the kinds of things that Sagar pointed out, I imagine that addictions programs could implement many of these activities as a part of the care that they offer, particularly in 
day and residential formats. Maybe the challenge is thinking about how we can extend some of these interventions to treatments that are, by their nature, more brief. However, where clients actually do have high rates of co-morbidity that perhaps aren't being recognized, we are targeting just the tip of the iceberg. We have to see how we can extend that to a deeper understanding of what is going on and what can be done. The encouraging thing, of course, is those two areas [mood and anxiety] are the most common co-morbidities of addiction clients.

Considering Julian's presentation: what a great example of collaboration at the systems level and working with people. The lesson is really that when you roll up your sleeves, work with people, and discover a common cause, you can make things happen. It is really nice to see the stages-of-change model used beyond the level of the client as a single person and to employ it as a useful construct for thinking about systems change, because I think it does have a lot to offer in terms of how you intervene. We all want to get to the "action stage" but actually many systems are precontemplative or ambivalent. So how can you get them to think about change in ways that they can start to prepare for it, and actually do it over time? The other thing about that which is really important is the whole issue of attitudes, values and beliefs. I think this comes up in a lot of the training. You really want to start at the knowledge and skill level with people and say here are the things that you need to be doing. However, it's important not to forget to give people permission to have their crazy attitudes, values and beliefs and to make it okay to get them out in the open and included in processes of dialogue, because we all carry stigma about the work that we do with the client population. We all have apprehensions about finding ourselves working with particularly difficult populations. I think an enduring challenge is how we give ourselves permission to try to make change and also to be able to deal with the kind of difficulties we have about some of these things we are trying to do, and what it means for us both personally and as teams.

One of the questions that comes up for me is, why screen for concurrent disorders? In a way Sagar has cautioned us to be ambivalent about screening. If you think of the quadrant model, it is less about where the clients are than about where we are. The quadrant model describes our world and that is why it is useful. It locates the people that do work with the clients, and you have an addiction side and a mental health side. If you are screening, and you have a mental health only service, or an addiction only service, maybe you are screening people out. What you want to find are the people who shouldn't be coming here, who we don't want to work with. However, if that is really the idea of screening, then that is problematic.

Paul mentioned what is probably the most common screening method that we use, and that is waiting lists. We screen people out by denying them access at the point they are asking for help, and then we set up ordeals they have to go through. The ones who show up at the end of that ordeal get the service. It is a way of culling and getting people who actually are the most ready, who are willing to do the craziest things to get the things they are looking for. The other ones who are ambivalent about the service, or whatever, just go somewhere else or get lost out there - we don't really know what happens to them. Now Sagar points out that there are things you can be doing with people while they are waiting, such as biblio-therapies, giving them information. The evidence actually is that this is change producing, so maybe we should challenge ourselves - even while we accept the reality that people may have to wait- that there are engagement activities that we can be directing them to through websites, through mailings, and giving them through groups. There are a number of things we could do better, I think. So maybe we should be challenging ourselves a bit more actively about that because these things can be change producing for people. 
If we recognize that there is a high co-prevalence of addiction and mental health problems, we want to screen, because we want to identify people who have complex problems and we want to make responses that really are sensitive to those problems. One of the goals of capacity-building for concurrent disorders is making programs CD-capable. In my simple-minded view this means that everybody is able to screen, identify and refer, and take preliminary actions such as the first level of responses that Sagar was referring to. That really should be a standard that we challenge ourselves to meet. Otherwise we are going to continue to have mental health-only and addiction-only services. So I think we have to decide, do we want a world that is set up like that, or do we want a more CD-capable world. It seems to me as we build a CD-capable world that the people who work in it have an entitlement, and the entitlement is to support. So it needs, actually, a higher level of service. We need $\boldsymbol{C D}$-specialized services that can do specialized assessments that can take really complex cases that these programs are going to find, as well as provide support, training, consultation, and tertiary services. So the world that I would really like to see us building would be CD-capable, and broadly based across the set of communities in Ontario and even the rest of Canada. Further, they are supported by hubs of services that are CD-specialized; and the "client" for these specialized resources, is as much the CD-capable system than any individual client. Referrals (to CD-specialized services) would come from people who are identifying and helping clients with complex problems in CD-capable systems of care, whom we would support consultatively as well. Becoming more able to identify, engage and help people with complex problems is why we are having this dialogue on screening and assessment. That we become better able to do that should the measure of whatever models we build and of whatever changes we make.

Christine Bois: I am Christine Bois and I work for the Centre for Addiction and Mental Health as the Concurrent Disorders Knowledge Exchange Priority Manager. I am talking to you today about screening for concurrent disorders from a systems perspective. When Wayne just said that there isn't such a thing as a system I thought, there isn't a system, there is actually a patchwork. When you look at the province from a regional perspective, we have a whole lot of different patchworks. In fact, some have primary care physicians that work very well with the addiction agencies and with the mental health agencies, while in other systems they don't have relationships to physicians. Other systems may have good working relationships between the addiction system and probation officers, and in other systems the judge tells them what treatment program they are going to. So you have great variation within each system around the province in terms of how the sectors work together.

When you think about how services work together at a provincial level, we also have some variations There are directors who will meet together a couple of times a year; they will email; they'll communicate around administrative issues, policy issues, and planning and funding issues. Within the addictions system there is this level of communication and that is a system of sorts. In the past, when we tried to increase referral rates, and increase cooperation within the systems, many of the agencies would write these memorandums of understanding; basically memorandums of agreement. So the directors would get together and after another six months of talking, they would fashion these wonderful kinds of statements that made a lot of sense to the directors, but in the end it didn't change a lot of the practice at the front line because many staff didn't even know agreements had been written. Often, they were even more of an administrative nature than about collaborative service or referral routes; Now we are beginning to talk about pathways to services that contained criteria as to who would accept who, and how the client would get there. This is a 
more practical kind of agreement. When you are looking at referral rates, and Sagar mentioned low compliance with referrals, I think what is really being said is that the referral process isn't working, not that the clients aren't being compliant. Rather we, as providers, aren't doing a good job of helping the client find how to arrive at the services they need. I have seen it in the past where, all to often, people are told where to go but they are not told how to get there. We don't understand how the client needs to get there or why the client can't get there or what the barriers are in place for the client. I would also suggest that, from a systems perspective, if we really wanted to increase collaboration across systems, and within systems, we really have to look at the whole referral process and have people understand how to help the client get to the next step along the way, or to the next agency. So the actual process of referral is important if you want to think about having a system and helping people get to where they need to be. I was also thinking about what does a system mean; what does collaboration mean in a system? Is it just about communication because when we look at the patchwork that we have now, there is whole variety of collaborations, some of which work much better than others.

The second thing that I wanted to comment on is the whole concept of implementing evidence-based practice within a system. We talked about the assessment tools project that we conducted in the past, and which a number of us here were involved in. We've looked at our implementation strategies; we've looked at what worked; and we've looked at what didn't work. When I look at some research projects, where you work with maybe four agencies, you have probably chosen those agencies who have agreed to participate in your research, or agencies who have the early adopters. They are at a stage of change where they want to participate. They see some advantage for them, for their agency or for their clients. When you try to do this at a provincial level, with all of the agencies, you are up against much more complicated working terms of trying to get people to adopt tools. We're not daunted; we have started another project on screening tools, and this time screening in addiction agencies for mental health problems and screening in mental health agencies for addiction problems. We hope to learn from our mistakes and have involved Linda in the project. We are laying out the criteria for the tools we will choose and reviewing the tools. That's the real easy part of the process. The process that is important is how we communicate to the mental health and addictions field about the advantages that we think these tools have for them, namely, that we think these tools bring an advantage for their clients. Marketing can convince us to use all kinds of products that we absolutely don't need and which are absolutely useless and do nothing but pollute the environment. Marketers are very successful at marketing products to us. Why then can't we market products to addiction and mental health agencies that we think are having advantages for them and for their clients? I think we look at the ways that we can reach these systems, we really have to look at what is important to them and what can they buy into. This is what gets to be the complicated and tricky part. This is just as tricky as the process of getting clients to be compliant with a referral. We have also talked about building readiness and about collaboration strategies, but I really think we have to be clear on selling people the advantage to them, and that it is not going to cost them more money; it is not going to increase their waiting lists; and it is not going to make things more difficult to them. I am also going to take a slightly different view of the notion that, if you screen for things that you can't do anything about, it is dangerous. I recognize clinically there are dangers in that but, at the same time, we continue to treat people without knowing about their problems. If we don't start screening, we are not going to recognize those problems that eventually we need to develop and provide services for. When I first started working in mental health 30 years ago, in a mental hospital in Ontario, I was seeing all these women who were 
depressed and were being trotted off down the hall to get ECT. I was supposed to be talking to them therapeutically and it wasn't really working. I look back on it now and I think probably many of these women were abused and we didn't know that at the time. We weren't even recognizing what abuse was, and it wasn't until we recognized what abuse was that we started to develop services and support for these people. So, in fact, if you don't screen, and you don't begin to identify what is there, you are never going to change the way the systems and services exist.

Steve Lurie: I'm Steve Lurie from the Canadian Mental Health Association Toronto Branch and my job here is to respond to some of what we have heard today and also give you a perspective from the Behemoth next door; the mental health system. So let me start with Linda's presentation.

I think she clearly identified the challenges in implementing screening tools and some of the lessons learned, but also that it can be done. It also reminds me of about 15 years ago when Linda and I were at a workshop with Native mental health and addictions workers and they kept denying that they wanted anything to do with screening because that was a product of white man's society. Then Linda began to talk and it was like watching a sponge soak up water. The tipping point occurred when people were given practical assistance with screening tools.

I think Sagar's presentation to us was really inspiring and I keep thinking if that WHO workbook has an addictions component we should just figure out how to move that into the mental health system and say, here are some things you can do. It is really practical because I think there are benefits. The interesting thing is that there are developments outside our usual system lens. This was directed at primary care and we often don't even know that those things exist. We have to ask ourselves how can they be used in our settings because I think we are constantly going around reinventing the wheel when somebody else already has a wheel that runs right and has enough spokes. Julian certainly showed us good ways in which system collaboration can occur and that it is all about relationships.

What I want to do now is move on to describing the mental health "non-system", because I think we have to realize that we have an addiction system that is wondering whether it should integrate with the mental health system. Here is the mental health nonsystem just for those of you who are wondering what it looks like in Ontario and don't come from here. We spend two billion dollars annually on mental health services. Some of that money is spent for primary care physicians and psychiatrists who bill according to our OHIP schedule, and there really is no overarching framework that defines what independent medical practitioners should do in the area of addiction and mental health care, other than best practice guidelines. You also have psychiatrists and other professionals who work in the general hospital sector that has about 2500 mental health beds as of today's date. In this sector you hear the term psychobiological as opposed to psychosocial interventions. Here is a real split because some of the folks in the community look at the hospital sector and say you know we aren't into clinical stuff; we don't care about diagnosis; we are into giving the consumers what they want. Often hospital programs are key referral sources for community based housing and case management, and there are some very effective reciprocal relationships in place. At the same time hospitals complain that they can't get people into community programs and some community programs are concerned about the lack of psychiatric back up available to community providers.

Then you have specialty hospitals, which are the old provincial psychiatric hospitals, and again you've got real variation in how those programs are organized. For example, in the general hospital system some of them have addiction services, some of them don't. Some of 
them have children and youth services for mental health, some of them don't. At the same time, the provincial psychiatric hospitals, or the old specialty hospital system, largely don't have an addiction service with the exception of CAMH.

Then you have the community. The community sector probably has about 200 organizations in it; some are very large, some are very small. The community mental health spending this year includes about $30 \%$ of its money for outpatient program in the general hospital sector and the target spending this year is $\$ 463$ million dollars, and the addiction sector is about $\$ 178$ million so, taken together, you've got almost $\$ 600$ million in spending. Translate that into the number of people served, and the number of people working in both systems, and you can see you're talking about a lot of people and a lot of clients. In terms of population characteristics, in 1992 on any given day there were 34000 people getting services in community mental health programs, or at least registered with a service. About $50 \%$ of them would have been classified as having serious mental illness and the rest didn't have serious mental illness. An interesting thing, reflecting on what emerged at the time, is that nobody asked any questions about substance abuse problems, so we didn't have any information about that. In 1998 we did a snapshot, which tried to compare information that was collected in the general hospital system, the provincial psychiatric hospital system and the community system. We got data on 27000 clients that we haven't started to use yet, but again we had no information about substance abuse issues. We didn't even ask the question. Now we have moved a bit farther and there is a data system in place for the addictions sector (DATIS). It asks mental health questions. Also the CDS (Common Data Set) that is based on the PSR Toolkit, the client data base for mental health that contains aggregate data from all community mental health programs, is now going to at least ask the question about the presence of concurrent disorders. If you look at the 3000 people in Ontario being served by assertive community treatment teams, which is where you might expect to find concurrent disorders, $27 \%$ appear to be listed as having concurrent disorders. This is far below what the literature would suggest you are supposed to find in ACT teams, typically in the 40-60\% range. This rate could be a result of missing data or lack of agreement on how to code concurrent disorders, that is, whether we code based on diagnosis, screening or assessment, or observed behaviour.

So where are we now? I think we have this challenge about how do you use common assessment tools across the system. In thinking about this I was helped by James comment yesterday about the difference between screening and assessment. However, I think the dilemma for many of us is we often don't have a choice of," Are we going to screen?" and then "Are we going to assess?" because the people are already at our door. There is a human service and justice initiative rolling out; people with mental illness and concurrent disorders are going to show up in safe beds, referred by the justice system and the field is going to need to know what is going on and what to do about it. It is not going to be like you have a lot of choice, or a lot of time to screen out. So some of those tools, like the K6 and the K10, may be quite helpful in at least how you build a treatment plan, or a plan of intervention. Just to put a spin on that in Toronto, there are 5000 people a year who are in contact with the police or the courts by virtue of their mental disorder. That is a huge number of people who are going to be descending on the services and we know from what people in corrections tell us that about $60 \%$ of the folks who are in the correction systems have a concurrent disorder. So this is going to be a big issue and big challenge for the field.

There is a question about how you use all this information we collect. Whether it is in a database, or whether it is a screener or an assessment tool, it should drive improvement in clinical behaviour; it should improve access to care; and it should lead to better outcomes. 
Now one of the debates of course is whether we can come up with the one screener or the one assessment tool, and we are having that debate in mental health. You probably have that debate in addictions. A couple of years ago I went to a workshop that the University of Toronto put on. They brought in international experts in the field of data management and information systems, and it was pointed out by Dr. Robin Fitzpatrick from the Oxford Dept. of Public Health that there are over 1275 assessment tools in health care, and growing all the time. There are 299 tools in mental health. He talked about the Oxford hip and knee screener, which is a 12 -item scale that can be administered through the general practice. They get a $90 \%$ response rate when the GP sends it out and it is now used to connect people to hip and knee replacements in the UK. It is also used to monitor their system performance. So I guess if there is a gold standard we can look to that may be it.

Finally, the last comment I'd make is to remind us all of the challenge of system integration, or non-system integration. There is a lot of work to be done here and we will have to begin by building relationships based on shared practice and learning. Helping both addictions and mental health services implement simple screening tools may be a good place to start. Our challenge is to do something that both sectors will see as helpful in providing quality services. Otherwise as they said in "yes, Minister" this may be like the law of inverse relevance that states that the more we talk about something the less we intend to do about it. Thank you.

\section{Audience Discussion}

Marilyn Herie: Going back to yesterday, I've been wondering how we actually disseminate these tools to clinicians, and how do we make them practical? I had a couple of thoughts on this and I'd be really interested in just some discussion or feedback about it. One thing that struck me is we were talking a lot about reliability and validity, which relate to how the test was administered and how well it does. What about the clinician's attitude? What can we put in social marketing materials that would address those factors? Also, I am interested in the notion of cut-points, and maybe we can incorporate clinical tools that we can use as a follow-up based on what the person screens for. This is similar to what Sagar was talking about with the WHO materials. The third piece is about standardized screening and assessment tools and maybe we can also be thinking about standardized or widely available self-help tools. These would be materials that clinicians could use and access because I think we all have libraries and databanks of tools that we like to use but to make these widely available would just be a really great asset.

Paul Niesink: I'd like to speak to the cut-point issue. Our agency used matching methodology for years, actually Brian helped develop it for us. So we used the ADS, the MAST, the DAST, the GHQ, and a social stability score and each of those tests were scored in a way that would tell you what the appropriate treatment destination would be for those individuals. So it made it pretty idiot proof for us to administer these. The problem a lot of the clinicians in the field are currently having with the existing tools is that there is a decision tree for analyzing the information but a lot of those decision trees you can drive a truck through. So it is very vague in terms of how you could manipulate the system to process a referral in whatever direction you are looking to do that. So I really like the cutpoint idea.

Steve Lurie: I want to address the availability of tools because I think the government always wants somebody to use one tool. So, for example, here in Ontario there is confusion about whether the PSR toolkit, which is basically a database to measure psychosocial functioning, is really a tool or not. It is not; it is simply a database. On the other hand we have a project going on across the province, with some leadership by CAMH, to implement the Resident Assessment Instrument for Mental Health in inpatient settings, and now we 
understand in community settings. What is interesting about this is that the instrument itself has had one field test in a hospital setting across Ontario. There has been no testing for utility; there has been no comparison with other tools. When we surveyed the ACT teams we were interested in what tools they were using. We had given them information and said use the Toolkit to record your outcomes but we are not going to define your clinical practice. Well, we were surprised that about $65 \%$ of the teams are using the Camberwell tool (Camberwell Assessment of Need), which many of us hadn't heard of before but it is widely used in the UK, and also used in New Zealand. So what is the gold standard, or do we have to accept that you can't make people choose tools? The challenge will be how do you use the information that the tools extract; how do you put that into databases for planning purposes; and how do you develop a common language among people using tools. I think that is where the cut point comes in and whether it is $43 \%$ or not becomes really critical. But how are you going to get a professional who likes using the Camberwell to switch to the Colorado Client Assessment Record. I think making tools available and analyzable so that you can crunch the numbers easily is a very good step. Then I think what you have to do is convert that to how it is going to affect practice and change what is going on in the field. I think it gets back to what Sagar pointed out. In some cases it will be simple screening, and also simple interventions at the front line, because many of the community mental health and addictions programs don't have the luxury of gearing up intensive treatment. They have the same resource base that they had before the tool.

Unidentified Participant: I would like to address the issue of getting people to buy-in to the tool and then making the tool useful. I speak from the experience of introducing psychiatric rating scales. The first thing is to go back to the Prochaska model that has been talked about, and asking the clinicians who are going to be using the tool: do you have a problem in this area that you would like to fix or quantify in some way? Most people, when they reflect on their own practice, say they would like to quantify it a little bit better, like I do a blood pressure test. However, if you'd have asked them or told them "I've got a great rating scale for depression, would you like to learn it?" they would probably say no. Get them to reflect first, and this is the Prochaska approach, and integrate it into their daily realities. Further, to use the medical example of grand rounds, you have one grand rounds or team meeting which is already scheduled and which is already a routine part of their life, where there is agreement that there is a problem they want to fix. The second step is the same kind of meeting but, after they have digested that they want to change, you then give them a simple tool and have them start using it. Our favourite way of doing this with psychiatric rating scales is do a little bit of the background first. What I do is I show a video clip. I don't explain the scale, but rather ask them to rate it and then we go through the items. People are uncomfortable because they have never seen this rating scale before and then I tell them you are going to watch a video clip and then you are going to use the rating scale. They read the items very carefully because they know they are going to have to score it before it has been explained to them. At the end of that as we discuss it item by item. We do it with them and in their own context, and do not try to do much more than that, like not making it part of a two-day event where you review all the possible treatments for that disorder.

Linda Sibley: Marilyn raised the point of counsellor attitude being paramount to the success of any kind of project. If you choose very simple tools, there are many in the field who will say this isn't sophisticated enough. They ask, "What is the reliability, validity, specificity etc." because they have training and have taken courses. They have studied well and will say this isn't sophisticated enough. We had that experience with the Drug Taking 
Confidence Questionnaire where there was a very long version which was much better at detecting confidence in avoiding drug use situations. However, because the field also says it needs to be brief, we chose the 8-item version. Of course you can predict what the criticism was. They then say this isn't long enough; this doesn't tell us all that we need to know.

The other issue around counsellor attitude is that we all bring our personal philosophy about change and about people with mental health and substance abuse, and it I think it is a challenge to find a common ground. One of the best things about Ontario's assessment tool project is that it took philosophy out of the treatment planning. You could in fact believe that addiction was caused by A, B or C and still effectively administer and interpret the tools and match people to a treatment program that made sense to them based on their philosophy, and not on your own. Some of the beauty of that was lost on the population that is administering the tools but I think that that possibility still exists. The tools in many cases were not administered in the way that we meant and I think it does go back to counsellor attitude. None of the tools were meant to be handed to someone in a waiting room to fill in, just to place it in their file, and if it is ever of any use we will have a look at it. That is in fact what has happened despite really clear instruction in many forms of training, (e.g., face-to-face, CD-Rom).

Unidentified Participant: I just wanted to pick up on both Sagar and Linda's point. It seems to me that how people learn is also a critical ingredient to success. In our own agency we have been doing some work on concurrent disorders and have to recognize that not all people think about concurrent disorders the same way. With respect to the training I think that the challenge is to ask people how they learned and what was useful and is there going to be some integration in training as to what you are now going to be doing differently in your practice. When we asked our staff how they like to learn, what came back is they didn't just want training, they wanted case-based training. They wanted mentoring and it had to be practical. In other words, you have to think about how you build it into the supervision process. Otherwise it is a one or two day shot and people won't use it. It will go into the file as Linda said.

Julian Somers: It is interesting that, while the term consumer-based care had emerged not so long ago as a rallying point, it certainly hasn't significantly penetrated the treatment organizations and systems. Indeed the three responses so far seem to be focussing on clinician-based reforms at the level of interaction with individuals. I think that is really a key point across this whole area of reform and I wanted to contrast it with another catalyst for the utilization of standardized information gathering tools, namely accountability. In broad strokes, the mechanism of transferring funds to the provinces and to the regional health authorities is "cash for accountability". So consideration of good measures is often stimulated by the need of regional health authorities to be able to funnel information back that it is in fact reliable. The train analogy works here but I would prefer the millipede analogy so that there isn't some big engine pulling the process but rather there is attention on how all the legs are working together to propel something forward.

The last point I wanted to make had to do with self-help instruments. Occasionally I have spoken with health authority executives who are responsible for health care across the board, and an interesting theme that is coming up in that forum is the sense that the population is kind of running rampant in its demand for services. The expectations are out of control and it is almost an impending stock market crash that we are fuelling the demise of our own system through escalating demands that are in fact out of scale with our capacity to respond. Perhaps these demands are surfacing because of our anxiety and now it becomes like help-seeking behaviour to reassure us the system is functioning. Further, as the star of mental health is ascending in health care, I think it is really important to have the 
strong evidence base of self-directed materials as part of the solution to the problem lest we appear to be just a further huge burden that is not being addressed adequately.

Unidentified Participants: I like the millipede idea although your example was more about the right of funder to stipulate the deliverable, and I think that is true. Regarding these changes in Ontario, the Ministry has played a very important role in this, and that is important to respect. Agencies have a right to set standards for practice in their agencies. Disciplines actually have a right and a demand placed on them to set these standards, and clinicians need to be constructively involved and critically engaged in those processes. We need to come back to the ultimate collaboration which is with the client and at various levels. You are right to point out we are most comfortable in talking about the individual in need of care but if we think of it in systems levels the client becomes a higher level entity than that. I think the idea of standardized self-help tools tosses out a good challenge to clinicians. We could be giving such tools to people, and I want to add families and other people affected to that list, because I think there are lots of ways of influencing change and supporting systems. It means getting out of the box, and the box for clinicians and agencies are our offices, as places where the exchanges happen with people that have problems. If we think of some of these virtual ways that we can start getting things out there, like using websites and the like, maybe we need to be moving around a bit more and engaging people in the locales where their problems are happening. I think that kind of out-of-the-box thinking would challenge the ways that we deliver our services and the ways that we can be helpful to people.

Greg Greaves: I have a brief question about the value of embedding a brief therapeutic tool within a standardized structured intervention. As an example, suppose you have administered a measure of severity on psychological and physical dependence and the results are known to the therapist. You, the client, are coming in for a structured psychosocial assessment and before that assessment begins the therapist has the opportunity to say to the client; "this is how you have scored on this instrument; this is what it means in terms of your physical and psychological dependence to alcohol and drugs; this is what other normative populations typically experience relative to this level of dependence; and what does that mean to you?" You use this to allow the client to process and understand and get insight into their own behaviour before you move into a really structured regimen using that as a tool to try to motivate and engage the client. I'm wondering what the value is of that approach in your view?

Unidentified participant: What came to mind immediately was project MATCH and the conclusion, or at least the inference that many people have made, that this was essentially an assessment intervention. This explains not only the parody of findings but also reflects on the fact that the assessment process exceeded the time spent in therapy. There are other examples where the assessment is used as the intervention with no deliberateness on the part of the therapist to actually do much of anything except to reflect back results. This leads us to consider the need for many individuals to be guided through a process of insight development, which might be overestimated on our part as clinicians.

Linda Sibley: What you have asked us to comment on is really the essence of using motivational interviewing during the course of assessment, and that is in fact what we do. The art of it is to balance what you know from training and experience; the answers to the assessment or screening questions you ask; and this abyss between what you feel needs to happen and what the client is suggesting they need you to do. This is the art of bringing yourself and the client closer through the course of the assessment and in generating a treatment plan that makes sense. In some ways that is how we decide whether the person is treatment-ready simply by gathering and collating the information 
that we have, session after session often from the very rich information that you gather. So it is about lessening the distance between yourself as the clinical side and the client who has expertise in what they know about themselves, what they feel they need, and what they have experienced previously and putting that all together in a treatment plan that makes sense.

Steve Lurie: One of the things that came up earlier was the cultural factor and I know from some of the work that we are doing in the Somali and Tamil communities that often you are not necessarily going to get the information needed in the first interview to assess the client. You may need to get collateral information from the family. How do you incorporate that; how do you incorporate narrative; and how do you get the questions? That is a huge challenge in many of our communities and in northern and remote communities as well where the science approach with a standardized assessment tool may not fit.

The second point that I would challenge us all to remember goes back to Sagar's comments. If you look at the Ontario Mental Health Supplement from 1994 it showed that well over $50 \%$ of people with mental health problems come in from primary care; they come in through the family practitioner. This is not a conversation we only have to have in our two specialized systems, but rather has to be a question about how to converse with primary care. What is the role of the addiction and mental health systems as being resources to the primary care system? What is the role of the mental health system (or non-system) as a resource to primary care? Increasingly, there are opportunities with the development of family health teams here in Ontario and I think the work that Julian was talking about attempting to integrate primary care and specialized services in other provinces is very important. It seems to me if we leave out the primary care aspect we are leaving out the point of access for probably $50 \%$ of the clients.

Brian Rush: I would like to bring this back to our discussion yesterday about dimensional and diagnostic distinctions and approaches to screening and assessment. There are two things this morning that I think bring us back to that discussion. Firstly, when Sagar puts up a slide that says "do no harm", it poses the question "why search for a diagnosis if we can't do anything about it, since there is a potential to stigmatize and label that person and create a big problem that we don't know what to do with?" Secondly, when I hear the discussion regarding how we create change, this takes me to the Roger's Diffusion of Innovation Model and other conceptual models we have for thinking about how to create clinician and organizational change. One of the fundamental principles of this model is not to ask them to do something too big right away as a first step. I ask what is your perspective on the diagnostic approach to screening, thinking about these two threads that came in today? I don't necessarily think that taking a diagnostic approach or sending up a red flag around diagnosis means you have to provide an intervention for that diagnosis. That is another very important thing that came up in the discussion last night. Having a potential diagnosis or diagnostic red flag might mean you do your core business differently. Perhaps we need to schedule appointments in a way that makes more sense for a person who may have a borderline personality disorder and just won't show up otherwise. Or perhaps we need to do something a little differently with the care plan. I don't know if a diagnosis only means you have to treat that disorder.

Wayne Skinner: Regarding risk, I found myself thinking of an observation Michel Fouceau made when someone was asking whether something isn't dangerous, and Fouceau said "everything is dangerous". It is true there is risk in everything and this is why the howto part of the conversation is so important in doing assessment and screening. It is not just doing these things, but how you do them determines whether they are going to work or not or whether they are going to do harm. There are lots of ways these things can be very 
problematic for people. Your question makes me think back about 20 years when I worked with Lynn Kozlowski at the ARF researching smoking cessation. Lynn had this idea that since we had some people in treatment at our facility, why don't we ask them about their smoking behaviours. They were not there asking for help with smoking, but the truth was over $80 \%$ of our clients were smokers. When we asked people in the field, and there was even literature on this, they said these people are pretty fragile and you shouldn't be talking about their smoking when we are trying to get them to cut back on their drinking; leave that for another day please. I think in the field now, we are dealing with schizophrenia and we are being very active about the idea that we should be helping them with smoking cessation. So you know I think there is value in identifying these things and moving forward on them even if at times how to deal with it seems strange. Generally, my feeling is that if you know something to be true, it is important to go to that and challenge yourself around solutions, rather than avoiding it because there is nothing we can do about it.

The other thing about the dimensional and diagnostic conundrum is that it isn't dichotomous. If you get stuck in it having to be an either/or thing, you are doing yourself a disservice. There are ways that diagnostic thinking is very important for clients with certain illnesses - it gets their entitlements. You are entitled to things because of your diagnosis. You need a diagnosis of heart disease to get heart surgery, or it has to be even more precise than that I imagine. When you are thinking of diagnosis there is inherent value in it. The problem with it from a clinical point of view is that it is dichotomous. It creates this box that people are either in or out, and that's probably not the way most of us work with people. When we work with people we notice that their symptoms change and shift and so dimensionality is very important when you are looking at the way clients progress or not. We really need to try and see how these ways of thinking can be valuable and maybe some of the ways they can be dangerous.

Unidentified Participant: I think it would be nice to try to have it both ways and I think it is helpful to also factor in the cost-benefit ratio. How can you have it both ways? Well, if there are simple measures that can generally be helpful then you are assisting people across a spectrum of severity and that is addressing the dimensional issue. To use a dental analogy, there is large preventative value putting fluoride in the water at relatively low cost and yet you still need the professional diagnosis of cavities to identify who requires high intensity, high cost, possibly painful interventions. So I think that we need to have a diagnoses to know where and when we are going to up the ante of the intervention. I appreciate your comments that knowing the diagnosis may just alter the approach in different settings and I liked your example of someone with borderline personality disorder. Perhaps we would be more forgiving of them if they didn't show up, and predict that they wouldn't show up for different kinds of appointments. However, where we would address the dimensionality aspects is just to have simple relatively cheap interventions, which we think would help everybody.

Unidentified Participant: Often you diagnose clients and the clients will reject it. That is the reality of the situation in the front line. I think a big piece of that is how it is communicated to the client by the clinician, the doctor, or the therapist and what you can do with them after that; the "do no harm" piece. The evolution of harm reduction, risk reduction, and strategies in the addiction field is a big step that we are taking. A few years ago the abstinence model was the only way to go and the ability to work in harm reduction and risk reduction practices has come along way from that. 